\title{
A Modeling Framework for Analyzing the Viability of Service Systems
}

\author{
Arash Golnam, Ecole Polytechnique Fédérale de Lausanne (EPFL), Switzerland \\ Gil Regev, Ecole Polytechnique Fédérale de Lausanne (EPFL), Switzerland \\ Alain Wegmann, Ecole Polytechnique Fédérale de Lausanne (EPFL), Switzerland
}

\begin{abstract}
Recent research has explored the principles of service system viability based on systems inquiry invoking perspectives from Systems Theory and Cybernetics in particular Stafford Beer's viable systems model (VSM). However based on Banathy and Jenlink (2004), Systems inquiry encompasses more than just Systems Theory and includes domains such as Systems Methodology and Systems Philosophy. Building on the extant literature, this work has the following particularities: 1) it is based on an explicit systems philosophy in which the authors explicitly define what they view as viability and, 2) it involves a systems methodological approach to either analyze the viability of a service system or to design a viable service system. This is achieved by means of applying a systems modeling technique called SEAM (Systemic Enterprise Architecture Method). SEAM rests upon systemic principles and embodies conceptualizations from VSM. The authors apply SEAM to concretely model a utility company in Geneva, Switzerland in order to gain an understanding of how a service system maintains its identity and remains viable in its environment.
\end{abstract}

Keywords: $\quad$ SEAM, Systems Methodology, System Philosophy, Systems Theory, Viable Service Systems, Viable System Model

\section{INTRODUCTION}

The concept of "service system" is central to Service Science and Service-Dominant (SD) logic (Vargo \& Lusch, 2004, 2008; Lusch \& Vargo, 2006). A service system is defined as "a configuration of people, technologies, organization and shared information, able to create

DOI: $10.4018 /$ jssmet.2011070104 value to providers, users and other interested entities, through service" (Maglio \& Spohrer, 2008). A service system delivers this value for as long as it remains in existence. Service Science researchers have therefore recently shown an increasing interest in studying the viability of service systems (see for example Barile et al., 2010; Saviano et al., 2010).

Following systems inquiry, this body of research uses Systems Theory and Cybernetics for understanding the factors that can contribute 
to the viability of a service system (see for example Barile et al., 2010; Saviano et al., 2010). However, systems inquiry encompasses more than just Systems Theory and Cybernetics.

Banathy and Jenlink (2004) proposed to conceptualize systems inquiry into three subparts: Systems Philosophy, Systems Theory and Systems Methodology.

Systems Philosophy embodies the fundamental assumptions about the domain of inquiry. Systems philosophy defines the worldview of the systems thinker. The systems theory and systems methodology used by the systems thinker depend on his or her systems philosophy. Banathy and Jenlink (2004) identified three aspects of systems philosophy, epistemology, ontology and axiology. Epistemology is concerned with the origins of the systems thinker worldview, or how we know what we know. Ontology is the worldview itself, the systems thinker's view of reality. Axiology defines the ethics of the systems thinker in terms of what is right or wrong, elegant or not. Of the three components of Systems philosophy ontology is the only one that is often made explicit. Epistemology and axiology remain implicit in most systems thinking discourse (for exceptions to this rule, see Weinberg, 1975; Vickers, 1968, 1987). But implicit or not, epistemology and axiology determine systems theory and methodology just the same.

Systems theory provides the set of principles that can be invoked to build an understanding of some aspect of reality. Systems theory refers to the science of systems that resulted from General Systems Theory (Bertalanffy, 1976). General Systems Theory provides "models, principles and laws that can be generalized across various systems, their components and the relationship among them". General Systems Theory is, in effect, a theory of universal principles that are common and apply to systems in general. Finally, systems methodology aims at the instrumentalization of systems theory and its application to a functional context (Banathy \& Jenlink, 2004). It involves developing models and methods to make adequate predictions or retrodictions about some aspect of reality and to learn how to control a phenomenon of interest in a desirable way (Klir, 2001).

Based on Banathy's Systems inquiry, our research has the following particularities. (a) It is based on an explicit systems philosophy, and most specifically an epistemology in which we explicitly define what we view as viability. (b) It involves a systems methodological approach to either analyze the viability of a service system or to design a viable service system. This is achieved by means of applying systems modeling.

Our epistemology is often called interpretive (Checkland \& Scholes, 1999). It defines a worldview where knowledge is created as a relation between an observer and the observed. The systems modeling reported in this paper follows our epistemological worldview.

In systems modeling we construct systems that are models of some aspects of reality (Klir, 2001). The first step of systems modeling process is for the modeler to observe some aspect of reality referred to as the "universe of discourse"(UoD). Employing a set of conceptualizations, the modeler then tries to distinguish a set of entities that compose the universe of discourse and the relationships between them. In effect, the conceptualizations employed in a model form a lens through which the modeler observes phenomena of interest in a UoD (Tarski \& Corcoran, 1983).

Next, the modeler develops a model in the representation domain. The model is composed of modeling constructs that represent the observed entities in the UoD. The conceptualization explains the kinds of modeling constructs in the representation domain and allows a mapping between the modeling constructs in the representation domain and the entities observed in the universe of discourse. A conceptualization thereby gives the modeling constructs a realworld interpretation. Figure 1 represents the process of systems modeling.

In this paper we follow the modeling process illustrated in Figure 1. A Swiss utility company called $\mathrm{SIG}^{1}$ (hereinafter referred to as Utility Company) is the service system that constitutes our universe of discourse. Our 
Figure 1. The modeling process

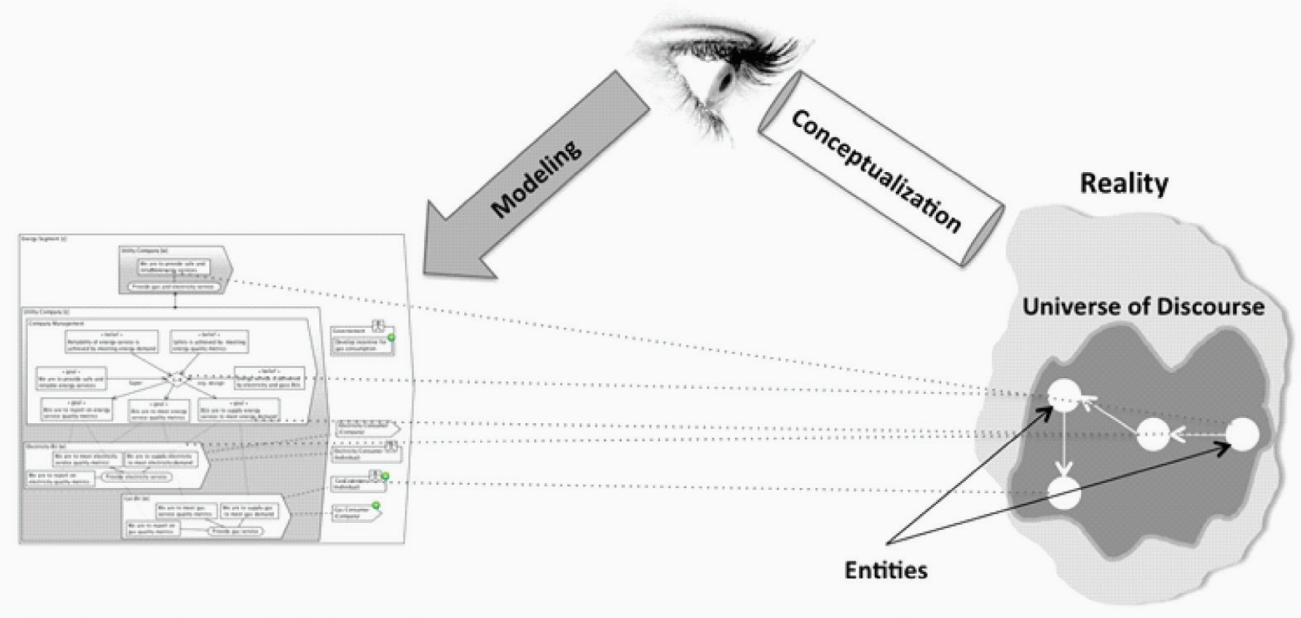

conceptualizations are derived from Stafford Beer's Viable System Model (VSM) (Beer, 1984, 1995).

In the representation domain we apply the Systemic Enterprise Architecture Method (SEAM) to represent and analyze SIG as a service system through the lens of our conceptualizations. SEAM was designed from the ground up with general systems principles (Wegmann, 2003). SEAM serves to analyze and assist in the design of business and engineering strategies. Developed at Ecole Polytechnique Fédérale de Lausanne (EPFL), SEAM has been used for teaching (Wegmann et al., 2007) and consulting (Wegmann et al., 2005) since 2001.

Our discussion is structured in the following way. In Section 1, we describe the conceptualizations we employed in the systems modeling reported in this paper. In Section 2, we model the utility company as a service system by applying SEAM modeling framework. In Section 3 , we discuss the related work and finally we present our conclusion and future work.

\section{CONCEPTUALIZATIONS}

As explained earlier our conceptualizations are inspired by Stafford Beer's VSM. We have the following justifications for the choice of VSM in this paper. VSM has been applied as a diagnostic tool to assist in the analysis and design of viability in a variety of contexts. For reports on the applications of VSM see Espejo (1989). Recently, researchers in the realm of service science have shown increasing interest in conceptualizing and modeling viability in service systems using VSM. A recent issue of the Journal of Service Science features insights and the inferences that can be drawn from VSM to gain a better understanding of viability service systems. Examples include but are not limited to Barile et al. (2010) and Saviano et al. (2010).

In this section; first, to gain a better understanding of our conceptualizations, we give a brief account of VSM, explaining its various parts and underlying concepts. Next, we describe a graphical representation of our conceptualizations. We call this graphical representation a "conceptual model". Figure 2 depicts a simplified representation of VSM.

\subsection{VSM}

Beer decomposes a viable system into a set of five systems. System 1 (the collection of operational systems), System 2 (the co-ordination), System 3 (inside and now), System 4 (outside 


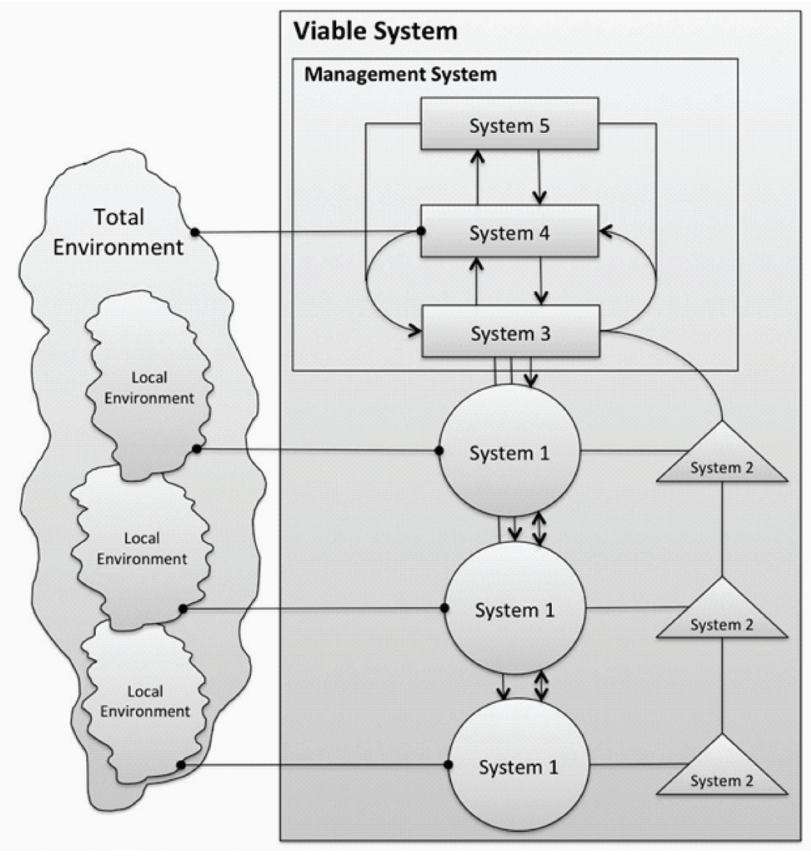

and future) and System 5 (identity). Stafford Beer $(1995,1984)$ refers to systems $3-5$ as meta-system of the management system.

\section{System 1}

Stafford Beer refers to the fundamental operations within a viable system as its System 1 . Operations create the outputs that justify the existence of the system from an observer's pointof-view. Hence, the functions of the System 1s (i.e., operational systems) are the reason that the system exists in the first place (Beer, 1995). Recursively, an operational system is in turn a viable system. This means, an operational system contains smaller operational systems and is contained in a hierarchy of larger operational systems. Thus, an operational system can be decomposed to its constituent operational systems. In Figure 2, we illustrate a viable system with three operational systems.

Asystem should interact and communicate with its environment in order to maintain its viability (Ashby, 1956). Channels enable the interaction and communication between the entities within the system and the entities within the environment. In Figure 2, the channels with arrows at both ends denote the interactions between the operational systems.

\section{System 2}

System 2 coordinates the various operational systems composing the viable system. It consists of a regulatory center for each element of System $1 \mathrm{~s}$ to ensure that the overall operations are running smoothly, and to deal with and recover from any disruptions and oscillations. In order to achieve regulation, it communicates the desired bounds of certain variables of the operational systems and monitors compliance. Regulation of the interrelated operational systems creates synergy and makes the system more than the sum of its parts.

\section{System 3}

This system directs the current and internal operations (i.e., "inside and now") and super- 
vises the coordination activities of System 2 . System 3 develops a black-box view of the System 1s (i.e., viewing only their inputs and outputs without knowing their internal functions and constituent systems) and looks for ways to optimize the overall efficiency and improve the performance of the operational systems by overviewing their interactions. System 3 exerts control over System 1s mainly using the vertical command channels shown on Figure 2.

\section{System 4}

This system deals with "outside and future". It guarantees the adaptation of the system as a whole to a changing environment. In doing so, it requires an understanding of the total environment in which the system is embedded; which is beyond the capability of the operational systems, as they concern themselves with their local environment, which is only a sub-set of this total environment. As well as interacting with the environment, System 4 needs to interact with System 3. This is because adaptation cannot be achieved without an understanding of the system, as it currently exists. In Figure 2, the round tip lines denote the interaction between System 1s with their local environment and System 4 with the total environment.

\section{System 5}

System 5 defines the ethos and the purpose of the system as a whole and monitors and strikes a balance between the activities of Systems 3 and 4. In other words, System 5 maintains the balance between the management of "inside and now" and "outside and future".

\subsection{The Conceptual Model, Derived from VSM}

Figure 3 shows a graphical model of our conceptualizations. We call this model the conceptual model. Compared to the VSM, in Figure 3, we decompose the management system based on the systemic functions that systems 2, 3, 4 and 5 perform for the system to remain viable. Three key functions are identified; homeostatic, heterostatic and identity.

This function-based re-representation of VSM assists us in translating the entities we observe in the universe of discourse to the constructs we employ in our models in the representation domain. Christopher (2007) gives a brief account of the functions that the management system performs in any viable system. Our conceptual model is partly inspired by his discussions. It should be clarified that a management system in Figure 2 may perform more than one of such functions at a time. Thereby, the model does not suggest a one-toone mapping between the management systems in Figure 2 and the management systems (i.e., System 3-5). We now explain the three key functions.

The homeostatic function focuses on maintaining the status quo and thereby Stability is an emergent property of the homeostatic function of the management system.

The heterostatic function deals with all sorts of improvements. Thus, Evolution and adaptation are the emergent properties of this function (Christopher, 2007).

Identity is invariance in some certain aspects of the system, in spite of all the changes that the system is going through. Hence, a system's identity is sustained only when a proper balance between stability and change is maintained.

\subsection{Viability}

Beer (1995) defines viability as the ability of a system to maintain a separate existence. Beer (1995) also adds that viability is a function of the balance maintained between stability versus adaptation. A system achieves viability by maintaining the aspects of its operations that are linked to its identity (i.e., the aspects that enable the observer to identify the system). Hence, when a system loses the aspects that 
Figure 3. The conceptual model of a viable system

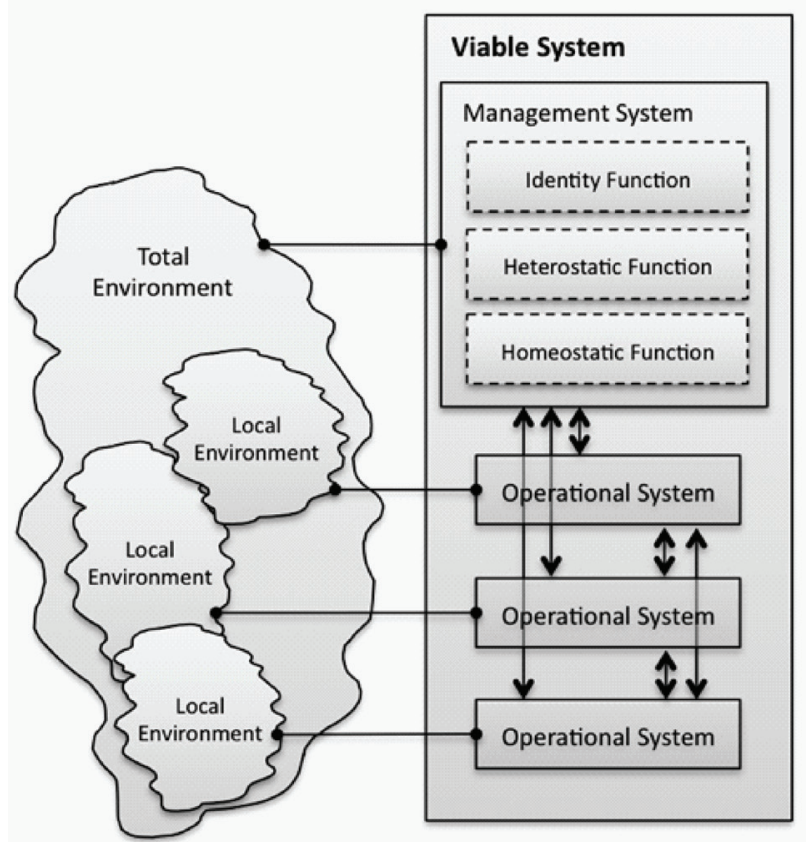

help an observer distinguish it from other entities, it passes out of existence for this specific observer. Maintenance of these aspects requires the management system to keep the state of some variables of the operational systems stable and/or precipitate change in the state of some operational systems' variables. This is achieved by performing the three functions outlined in the conceptual model. Recursively, the states that an operational system is to maintain or achieve constitute its identity from the point of view of the management system. Hence, the management system within each operational system is to ensure the achievement or maintenance of those states, for the operational system to remain viable.

Adopting this mode of reasoning on viability we can revisit the concept of value in service systems from a viable system perspective. Ma et al. (2010) defines value as the ultimate goal that the service system tries to achieve. This definition guides us in defining value as anything that assists a system in remaining viable.

\section{MODELING AND ANALYSIS OF VIABILITY IN A SERVICE SYSTEM}

In this section, we first briefly explain SEAM, its modeling notations and semantics by presenting a generic model of SEAM, embodying the conceptualizations outlined in the previous section. Next, we develop SEAM models of the Utility Company as a service system. The theoretical insights embodied in our conceptualizations and thereby in our SEAM model will contribute to our understanding of the mechanisms by means of which the Utility Company maintains its viability. Figure 4 is a generic SEAM model of a service system modeled in its market segment.

In SEAM a system is denoted by a block arrow and can be represented as a whole (i.e., black box) or as a composite (i.e., white box). Modeling the Market Segment as a composite we represent the service system and its total environment. The environment of the service system can comprise the service adopters, regulators and etc. 
Mapping the service systems in our SEAM models correspond to the viable system in the conceptual model in Figure 3, the service system can be decomposed to its constituent operational systems and a management system. Recursively, each operational system can then be modeled as a service system and decomposed to its suboperational systems and its management system.

A service system is characterized by its behavior and properties. In SEAM, behaviors and properties are respectively represented by ovals and rectangles. Service systems as wholes and as composites have behaviors and properties. We call the behavior of a service system as a whole "service". The behavior of a service system as a composite is called "process". This process captures the implementation of the service. Representing a service system as a composite we model how its operational systems and management system contribute to the service implementation process. The property of a service system as a whole captures the "identity" of the service system. The identity of a service system is expressed by a prescriptive statement that conveys what the service system is to do in order to maintain its identity and thereby sustain its viability.

As illustrated in Figure 4, we model the way a service system sustains its identity by considering maintenance of a particular identity property as a super goal and refining it to a set of (sub)goals. This refinement is a cognitive process carried out by the management system with the help of the beliefs it holds. Beliefs, in effect, represent the management system's interpretations of the state of service system and the systems with which the service system interacts.

Based on the explanations in Section 1.3, goals are grouped into two categories. The first category includes the goals that represent the changes that are to be made to some states of the service system. We refer to these goals as achievement goals. Goals in the second category specify the states of the service system that are to be kept the same and maintained. We call these goals maintenance goals. Achievement and maintenance goals respectively reflect the heterostatic and the homeostatic functions of the management system within a service system. The management system of the service system then, assigns goals to the constituent operational systems. These goals are to be considered by the service systems as the super goals and are thereby refined to a set of achievement and/or maintenance goals.

Going back to our discussion on the link between viability and value in service systems, it can be asserted that the super goals represent the value properties that the service systems tries to achieve to remain viable. Recursively, as these super goals are refined and decomposed to (sub)goals that are in turn super goal. Thus, we can assert that for the entities within the service system the value properties are refined and decomposed. This proposition rests upon the "partition and merge" characteristic of value in service systems as introduced in $\mathrm{Ma}$ et al. (2010).

Figure 5, is a SEAM model of the utility company interacting with "Electricity Consumer" and "Gas Consumer" (service adopters) and the Government in the Energy Segment (i.e., entities in its environment). "Provide gas and electricity service" is the service, the Utility Company as a whole, is offering to the service adopters. Modeling the Utility Company as a composite, we represent the "Company Management" (the management system in the conceptual model) and Electricity BU (Business Unit) and Gas BU (operational systems in the conceptual model) and their contribution to "Provide gas and electricity service".

In Figure 5, "We are to provide safe and reliable energy services" is the identity property of the Utility Company as a whole, which is then perceived by the Company Management as a super goal. The Company Management believes that "Reliability of energy service is achieved by meeting energy demand" and the belief that "Energy service is delivered by electricity and gas BUs" is derived from the organization design of the Utility Company (in the SEAM models, such goals are annotated by "org. design"). Based on these beliefs, the goal "BUs are to supply energy service to meet energy demand" is developed by the Company 
Figure 4. SEAM model of a service system

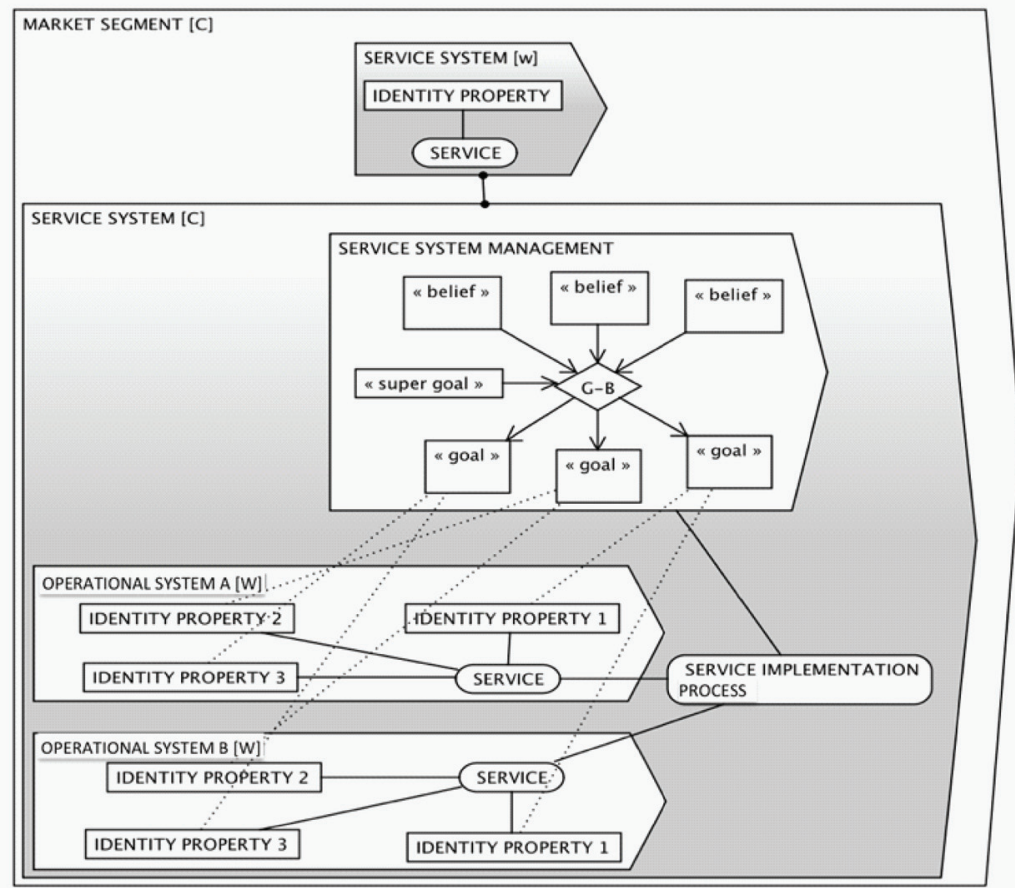

Management as a refinement of the super goal. This goal is then communicated to the BUs by the management system as their identity properties. The Gas BU interprets this goal as "We are to supply gas service to meet gas demand". Other parts of the model can be interpreted the same way.

The pluses in the Figure 5 mark the emergence of new entities in the universe of discourse. As it can be seen the government develops incentives for gas consumption. The new incentives lead to an increase in the number of the Gas Consumers (private and company).

In Figure 6, we represent the Gas BU as a composite. The composite view of the Gas BU, provides us with insights into the beliefs and the goals the Gas BU Management holds. The increase in the number of gas consumers leads to the belief "Demand for gas is rising". The Gas BU management also believes that "Gas supply is adjusted by increasing or decreasing the pressure in pipes" and the organization design of the Gas BU derives the belief that "Gas supply dept. adjusts the pressure in pipes". As the identity of the Gas BU is geared to meeting the demand, the BU management formulates the achievement goal "Gas supply dept. is to increase the pressure in pipes".

The Gas BU, on the other hand, is to report on and meet the gas service quality service in order to sustain its identity. As illustrated in Figure 6, the Gas BU believes that "Gas quality metrics deal with incidents" and "preventative measures reduce the number of incidents". Increasing the pressure in pipes gives rise to the belief "The number of incidents will probably rise". The rise in the number of incidents leads to the inability of the Gas BU to meet the super goal "We are to meet the gas service quality metrics" and consequently puts the viability of the Gas BU and the Utility Company in threat.

The belief " Analyzing incident statistics improves preventative measures" reflects how the Gas BU management plans to counteract the effect of the increase in the pressure in 
Figure 5. Utility company in gas segment

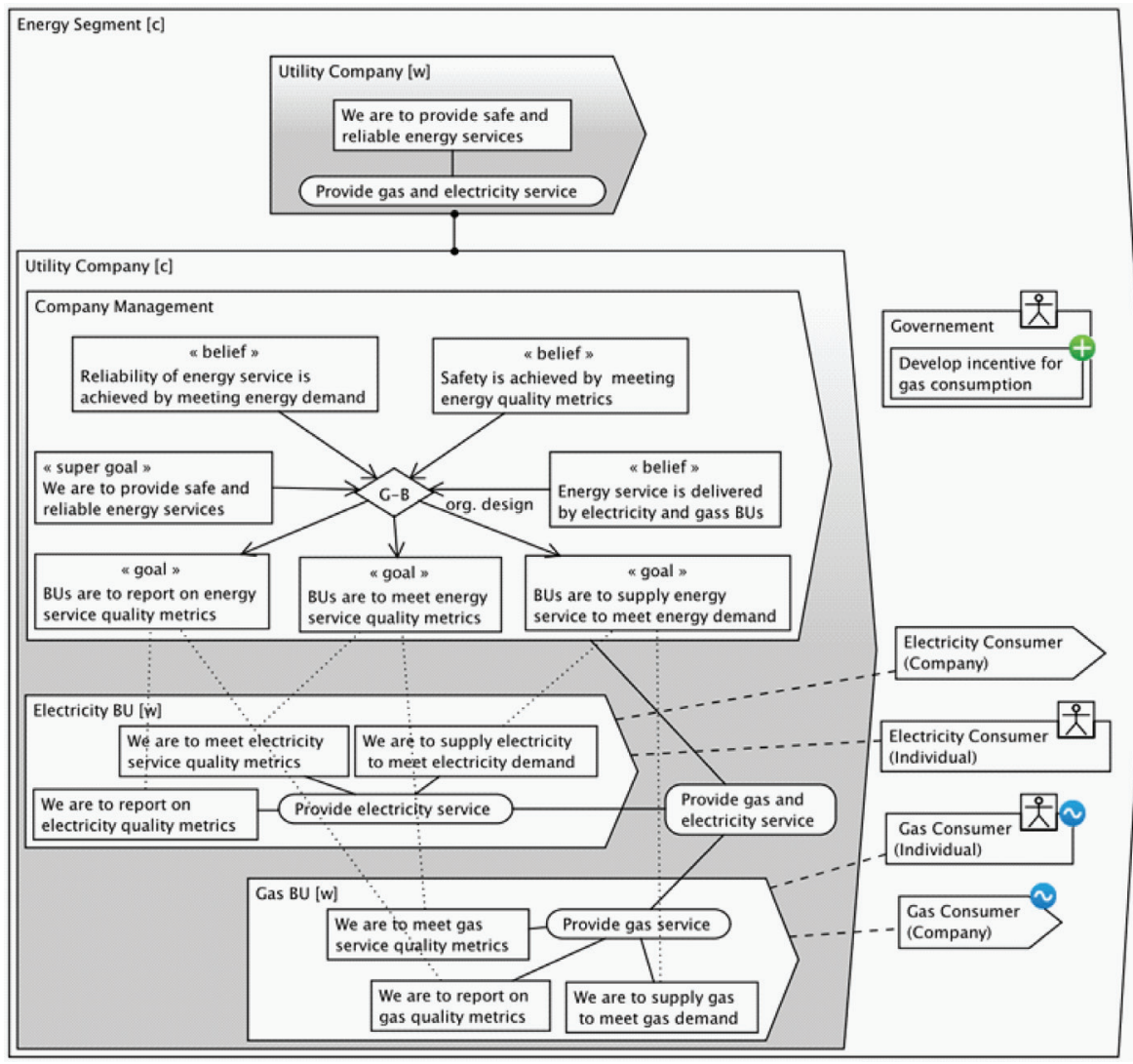

pipes. Analysis of incident statistics results in the development of more effective preventative measures and therefore decreases the incidents. As "Gas supply dept. is in charge of preventative measures", a belief stemming from the organization design, the Gas BU Management formulates the maintenance goal "Gas supply dept. is to analyze incident trends". Other sections of the model can be interpreted similarly. Representing the Gas BU as a composite we also model the contribution of its departments to the implementation of the "Provide gas energy" service.

In Table 1, we present a mapping between the conceptualizations, SEAM modeling constructs and some entities in the universe of discourse in the modeling process reported in this paper.
The method presented in this paper can be broadly categorized as a problem structuring method (PSM). PSMs assist decision makers in the structuring of the problems rather than solving them by identifying an agreed framework for their problem. The application of PSMs to wicked problems result either in a well-defined problem that can be addressed using traditional operations research (OR) methods, or a clarification of the problem situation that enables those responsible to reach a consensus or agree on a course of action (Eden, 1994; Mingers \& Rosenhead, 2004; Rosenhead, 1996). Our method can thereby, assist managers in the analysis of viability by gaining a better understanding of the organizational design as well as the control structures that can ensure viability in a service system. 
Figure 6. Gas BU in the utility company

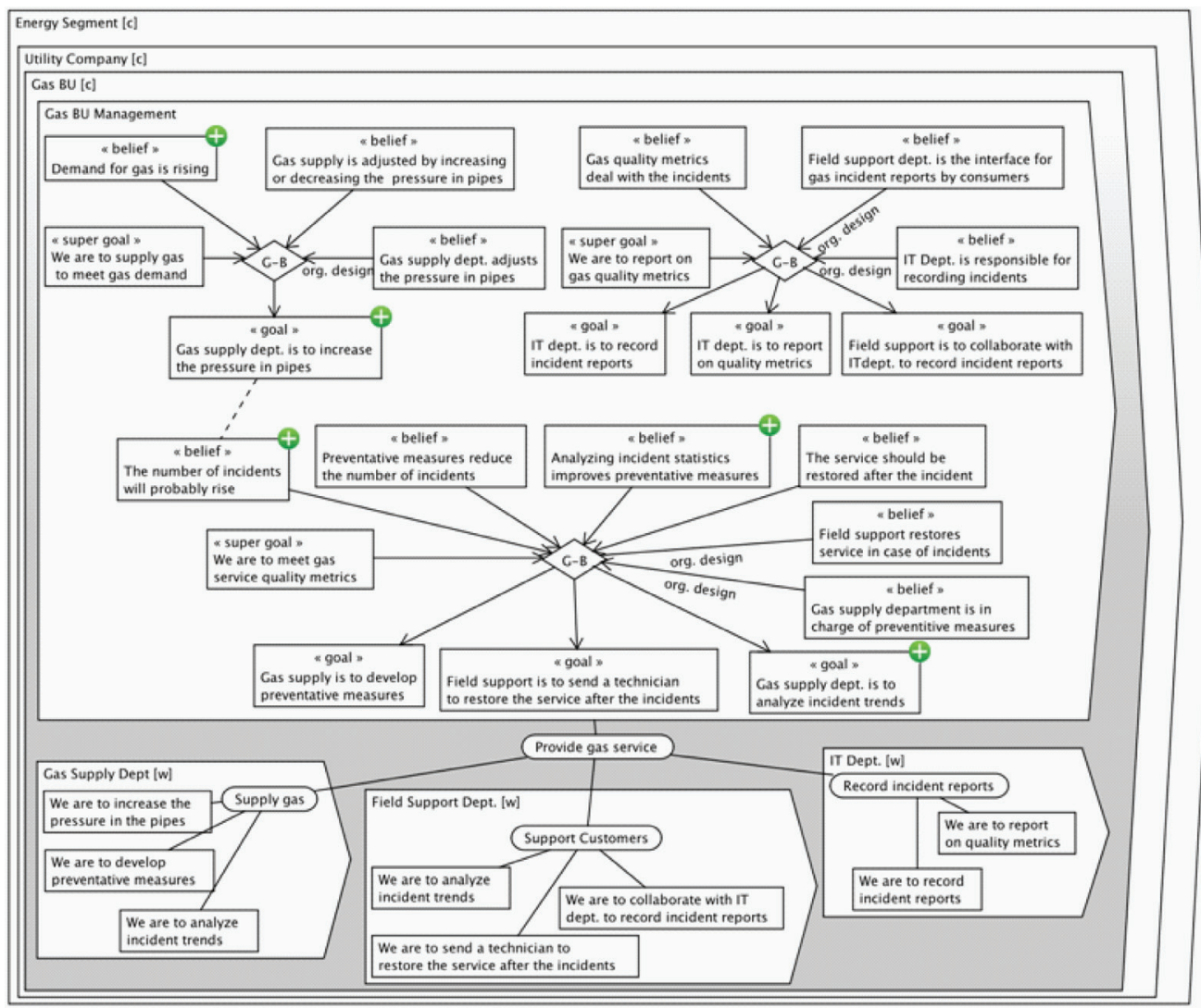

Table 1. Mapping between the conceptualizations, modeling constructs and some of the entities in the UoD

\begin{tabular}{|c|c|c|c|}
\hline \multirow[b]{2}{*}{$\begin{array}{l}\text { Conceptual- } \\
\text { izations }\end{array}$} & \multirow[b]{2}{*}{$\begin{array}{l}\text { SEAM Modeling } \\
\text { Constructs }\end{array}$} & \multicolumn{2}{|c|}{ Entities in the UoD } \\
\hline & & Utility Company [c] & Gas BU [c] \\
\hline $\begin{array}{c}\text { Management } \\
\text { System }\end{array}$ & $\begin{array}{l}\text { Service system } \\
\text { management }\end{array}$ & Company Management & BU Management \\
\hline $\begin{array}{l}\text { Operational } \\
\text { System }\end{array}$ & Service system & Electricity BU, Gas BU & $\begin{array}{l}\text { IT Dept., Field Support Dept., Gas Sup- } \\
\text { ply Dept. }\end{array}$ \\
\hline Identity & Super goal & $\begin{array}{l}\text { We are to provide safe and reli- } \\
\text { able services }\end{array}$ & $\begin{array}{l}\text { - We are to supply gas service to meet } \\
\text { gas demand } \\
\ldots\end{array}$ \\
\hline $\begin{array}{l}\text { Homeostatic } \\
\text { Function }\end{array}$ & Maintenance goal & $\begin{array}{c}\text { - BUs are to supply energy } \\
\text { service to meet energy demand } \\
\ldots\end{array}$ & $\begin{array}{c}\text { - IT dept. is to report on quality metrics } \\
\text { - Gas supply is to analyze incident trends } \\
\ldots\end{array}$ \\
\hline $\begin{array}{l}\text { Heterostatic } \\
\text { Function }\end{array}$ & Achievement goal & ---- & $\begin{array}{l}\text { - Gas supply dept. is to increase the } \\
\text { pressure in pipes }\end{array}$ \\
\hline
\end{tabular}




\section{RELATED WORK}

Service science is a fairly new field of research, dating to 2004 (Barile \& Polese, 2010a). Hence, most work in this area is very recent. The concept of service system has enabled researchers to see a service as a set of interacting providers and consumers who together provide value to themselves; hence, when the entity loses the aspects that help an observer distinguish it from other entities, the corresponding system passes out of existence for this specific observer and others (Barile \& Polese, 2010a). Quite quickly, value was linked to the notions of adaptability and survival within an environment (Vargo et al., 2008). System Thinking was identified as providing some of the necessary foundations for Service Science (Barile et al., 2010) in general and for service systems in particular. This produced the concept of Viable Service System (Barile \& Polese, 2010b) and resulted in the application of the Viable System Approach (VSA) to the study of the viability of service systems. VSA is a framework built on Beer's Viable System Model (VSM) (Beer, 1984) and other systems thinking concepts.

In Barile and Polese (2010b), the authors compare the fundamental concepts of smart service systems and viable service systems, highlighting the potential mappings between the service science and systems science principles. Godsiff (2009) explains the implications of the law of requisite variety within the service science and reasons about the mechanisms through which a system deals with the variety introduced by its environment.

Barile and Polese (2010a) describe the potential benefits of using network theory and VSA for service science. They also compare the contributions and viewpoints about services, marketing and management of these different frameworks.

There has been earlier research into VSM and services. Most notably Flood and Zambuni, (1990) provide an application of VSM to tourism services.
In the fields of requirements engineering and conceptual modeling there have been parallel research into services and value modeling. In Böttcher and Fähnrich (2010), the authors present a meta-model that comprise the concepts necessary for modeling service systems. The syntax and the implementation of the editor that embodies the conceptualization are then elaborated. The modeling process outlined by Böttcher and Fähnrich (2010) consists of the following steps: analysis; concept extraction; formal specification, and implementation. The first two steps can be mapped onto the modeling process reported in this paper. However we do not discuss the formal specification of our models in terms of their syntax and semantics, as this is a part of research in progress. The metamodel developed by Böttcher and Fähnrich (2010) comprises four inter-related sub-models; resource model: component model: product model, and process model that can provide the concepts required for modeling the service systems in general. The methodology presented in this paper rather focuses on structuring the problems concerning the design and analysis of viability in service systems, rather than a generic representation of service systems.

Business process modeling notation (BPMN) (White, 2004) is a technique to formally model and describe how business processes are structured and to represent the detail of such processes. In SEAM, the focus is building an understanding of the business as a nested hierarchy of systems. The modeler is thus interested in conceptualizing the systems that enterprise contains and the ones in which the enterprise is contained. Thus, an emphasis is put on understanding the systems, delineating their boundaries, the services provided by the systems as a whole (black-box view of the system) and the processes that implement these services in the system as a composite (white-box view of the system). In SEAM the behavior of the system is specified by modeling the processes in the systems. We might have a process in the market, one in the company, one in the IT department, 
one in the IT applications. In BPMN, there is usually one process that merges all these levels and abstracts away some. In short, SEAM is a system-oriented modeling technique whereas BPMN is process-oriented.

e3Service (de Kinderen \& Gordijn, 2008) is a method for semi-automatically reasoning about matching service offerings with customer needs. In order to make this semi automatic reasoning possible, e3Service assumes that the customer and supplier share the same ontology, that the customer specifies her needs in the same vocabulary as the supplier specifies its offering. In SEAM, we precisely avoid to make this simplifying assumption. This comes at the cost of enormously complicating automatic or event semi-automatic reasoning with the benefit of models that more accurately reflect reality.

$i^{*}(Y u, 1997)$ is one of the leading modeling method used in the requirements engineering research community for reasoning about functional requirements (FR) and non-functional requirements (NFR). i* provides modeling artifacts for reasoning about alternative satisfactions of NFR. $i^{*}$ models describe relationships as actors dependencies. Hence, $i^{*}$ offers support for reasoning about alternatives. $i^{*}$ has been extended with value reasoning in (Gordijn et al., 2006).

In our own work, we have explored the way we could model the value provided by a service with Vickers's appreciative system (Regev et al., 2011). Finally, this paper is an extension of Golnam et al. (2011).

\section{CONCLUSION AND FUTURE WORK}

In this paper we applied the SEAM method to the modeling of a service system viability. To do so, we extended SEAM with concepts from Beer's Viable System Model. With an example adapted from the real industrial case of a gas provision service by a utility company we showed how it is possible to model aspects such as adaptation to a perceived environment with aspects such as homeostasis and heterostasis. The modeling constructs in the SEAM models enable us to map the theoretical conceptualizations of viability onto the mechanisms through with a service system remains viable. We have also contributed to service science by adopting an interpretative epistemology where the concepts of viability, identity and indeed service are all dependent on the observer. Hence, the evolution of the gas service is modeled as maintaining its identity for its stakeholders. This opens the door for more research into reconciling the viewpoints of different stakeholders on what they consider as being "the same service."

Our future work focuses on augmenting the modeling framework with variety concepts and applying it to a prospective case in order to develop prescriptions on a viability compatible design.

\section{REFERENCES}

Ashby, W. R. (1956). An introduction to cybernetics. London, UK: Chapman \& Hall.

Banathy, B. H., \& Jenlink, P. M. (2004). Systems inquiry and its application in education. In Jonassen, D. H. (Ed.), Handbook of research on educational communications and technology (2nd ed.). Mahwah, NJ: Lawrence Erlbaum.

Barile, S., \& Polese, F. (2010a). Linking the viable system and many-to-many network approaches to service-dominant logic and service science. International Journal of Quality and Service Sciences, 2(1), 23-42. doi:10.1108/17566691011026586

Barile, S., \& Polese, F. (2010b). Smart service systems and viable service systems: Applying systems theory to service science. Journal of Service Science, 2(1-2), 20-39.

Barile, S., Spohrer, J., \& Polese, F. (2010). System thinking for service research advances. Journal of Service Science, 2(1-2), i-iii.

Beer, S. (1984). The viable system model: its provenance, development, methodology and pathology. The Journal of the Operational Research Society, 35(1), 7-25.

Beer, S. (1995). The heart of enterprise. New York, NY: John Wiley \& Sons. 
Bertalanffy, L. V. (1976). General system theory: Foundations, development, applications (Revised ed.). New York, NY: George Braziller.

Böttcher, M., \& Fähnrich, K. P. (2010). Modeling of service systems. International Journal of Service Science, Management, Engineering, and Technology, 1(4), 1-11. doi:10.4018/jssmet.2010100101

Checkland, P., \& Scholes, J. (1999). Soft systems methodology in action. New York, NY: John Wiley $\&$ Sons.

Christopher, W. F. (2007). Holistic management: Managing what matters for company success. New York, NY: Wiley-Interscience.

de Kinderen, S., \& Gordijn, J. (2008). E 3 Service: A model-based approach for generating needs-driven e-service bundles in a networked enterprise. In Proceedings of the 16th European Conference on Information Systems, Galway, Ireland.

Eden, C. (1994). Cognitive mapping and problem structuring for system dynamics model building. System Dynamics Review, 10(2-3), 257-276. doi:10.1002/sdr.4260100212

Espejo, R. (1989). The viable system model: interpretations and applications of Stafford Beer's VSM. New York, NY: John Wiley \& Sons.

Flood, R. L., \& Zambuni, S. A. (1990). Viable systems diagnosis. 1. Application with a major tourism services group. Systemic Practice and Action Research, 3(3), 225-248.

Godsiff, P. (2009). Service systems and requisite variety. In Proceedings of the Naples Forum on Service: Service-Dominant Logic, Service Science and Network Theory, Naples, Italy (pp. 978-988).

Golnam, A., Regev, G., \& Wegmann, A. (2011, February 16-18). On viable service systems: Developing a modeling framework for analysis of viability in service systems. In Proceedings of the Second International Conference on Exploring Services Sciences, Geneva, Switzerland.

Gordijn, J., Yu, E., \& Van Der Raadt, B. (2006). Eservice design using $\mathrm{i}^{*}$ and 3 value modeling. IEEE Software, 23(3), 26-33. doi:10.1109/MS.2006.71

Klir, G. J. (2001). Facets of systems science (2nd ed.). New York, NY: Springer.

Lusch, R. F., \& Vargo, S. L. (2006a). The servicedominant logic of marketing: dialog, debate, and directions. New York, NY: ME Sharpe.
Ma, C., Wang, Z., \& Xu, X. (2010). Preliminary discussions on several characteristics of service value. International Journal of Service Science, Management, Engineering, and Technology, 1(3), 50-62. doi:10.4018/jssmet.2010070103

Maglio, P. P., \& Spohrer, J. (2008). Fundamentals of service science. Journal of the Academy of Marketing Science, 36(1), 18-20. doi:10.1007/ s11747-007-0058-9

Mingers, J., \& Rosenhead, J. (2004). Problem structuring methods in action. European Journal of Operational Research, 152(3), 530-554. doi:10.1016/ S0377-2217(03)00056-0

Regev, G., Hayard, O., \& Wegmann, A. (2011, February 16-18). Service systems and value modeling from an appreciative system perspective. In Proceedings of the Second International Conference on Exploring Services Sciences, Geneva, Switzerland.

Rosenhead, J.(1996). What's the problem? An introduction to problem structuring methods. Interfaces, 117-131. doi:10.1287/inte.26.6.117

Saviano, M., Bassano, C., \& Calabrese, M. (2010). A VSA-SS approach to healthcare service systems the triple target of efficiency, effectiveness and sustainability. Journal of Service Science, 2(1-2), 41-61.

Tarski, A., \& Corcoran, J. (1983). Logic, semantics, metamathematics: papers from 1923 to 1938. Cambridge, MA: Hackett.

Vargo, S. L., \& Lusch, R. F. (2004). Evolving to a new dominant logic for marketing. Journal of Marketing, 68(1), 1-17. doi:10.1509/jmkg.68.1.1.24036

Vargo, S. L., \& Lusch, R. F. (2008). Service-dominant logic: continuing the evolution. Journal of the Academy of Marketing Science, 36(1), 1-10. doi:10.1007/ s11747-007-0069-6

Vargo, S. L., Maglio, P. P., \& Akaka, M. A. (2008). On value and value co-creation: A service systems and service logic perspective. European Management Journal, 26(3), 145-152. doi:10.1016/j. emj.2008.04.003

Vickers, G. (1968). Value systems and social process. London, UK: Tavistock.

Vickers, G. (1987). Policymaking, communication, and social learning. Piscataway, NJ: Transaction.

Wegmann, A. (2003). On the systemic enterprise architecture methodology (SEAM). Paper presented at the International Conference on Enterprise Information Systems, Angers, France. 
Wegmann, A., Regev, G., de la Cruz, J. D., Lê, L. S., \& Rychkova, I. (2007). Teaching enterprise architecture and service-oriented architecture in practice. In Proceedings of the Workshop on Trends in Enterprise Architecture Research (p. 13).

Wegmann, A., Regev, G., \& Loison, B. (2005). Business and IT alignment with SEAM. In Proceedings of the 1st International Workshop on Requirements Engineering for Business Need, and IT Alignment, Paris, France.

Weinberg, G. M. (2001). An introduction to general systems thinking (Anniversary, S., Ed.). New York, NY: Dorset House.

White, S.A. (2004). Introduction to BPMN.Armonk, NY: IBM Cooperation.
Yu, E. S. K. (1997). Towards modelling and reasoning support for early-phase requirements engineering. In Proceedings of the Third IEEE International Symposium on Requirements Engineering (pp. 226-235).

\section{ENDNOTE}

SIG merely serves as a concrete example of a service system to illustrate the applicability of our modeling framework. The information presented on SIG in this paper is based on the understanding we developed about various aspects of its service offerings and organizational structure, through a consulting project we undertook for SIG. 


\title{
International Journal of Service Science, Management, Engineering, and Technology
}

\author{
An official publication of the Information Resources Management Association
}

\begin{abstract}
Mission
The primary objective of International Journal of Service Science, Management, Engineering, and Technology (IJSSMET) is that of advancing the service sciences in their theoretical and practical aspects, serving as a vehicle for the development of service science, management and engineering (SSME) as a broad, multi-disciplinary research area including many disciplines as computer science, software engineering, operations research, management sciences, marketing, and psychology, among others. IJSSMET publishes original research papers, research notes, reviews, and cases on all aspects of service science, service management, service engineering and its supporting technology, along with papers related to service science education and professional aspects related to services. Both theoretical and practical papers are welcomed.
\end{abstract}

\section{Subscription Information}

IJSSMET is published quarterly: January-March; April-June; July-September; October-December by IGI Global. Full subscription information may be found at www.igi-global.com/IJSSMET. The journal is available in print and electronic formats.

Institutions may also purchase a site license providing access to the full IGI Global journal collection featuring more than 100 topical journals in information/computer science and technology applied to business \& public administration, engineering, education, medical \& healthcare, and social science. For information visit www. infosci-journals.com or contact IGI at eresources@igi-global.com.

\section{Copyright}

The International Journal of Service Science, Management, Engineering, and Technology (ISSN 1947-959X; eISSN 1947-9603). Copyright (C) 2011 IGI Global. All rights, including translation into other languages reserved by the publisher. No part of this journal may be reproduced or used in any form or by any means without written permission from the publisher, except for noncommercial, educational use including classroom teaching purposes. Product or company names used in this journal are for identification purposes only. Inclusion of the names of the products or companies does not indicate a claim of ownership by IGI Global of the trademark or registered trademark. The views expressed in this journal are those of the authors but not necessarily of IGI Global.

\section{Correspondence and questions:}

Editorial: $\quad$ Miguel-Angel Sicilia Editor-in-Chief

IJSSMET

E-mail: msicilia@uah.es
Subscriber Info: IGI Global

Customer Service

701 E Chocolate Avenue

Hershey PA 17033-1240, USA

Tel: 717/533-8845 x100

E-mail: cust@igi-global.com 